Campos Neutrais - Revista Latino-Americana de Relações Internacionais Vol. 2, No 1, Janeiro- Abril de 2020. Santa Vitória do Palmar - RS.

\title{
O bem-estar social e as políticas públicas destinadas à inclusão das pessoas com deficiência no mercado de trabalho no Brasil e em Portugal
}

\author{
Ana Paula Dupuy Patella Pase* \\ Caricia Hercilia Alves Oliveira dos Santos ${ }^{* *}$ \\ Danieli Veleda Moura*** \\ Marcia Leite Borges* \\ Manuela Medeiros Parada***
}

\begin{abstract}
Resumo: O trabalho respondeu como tem sido desenvolvidas as políticas públicas de inclusão das pessoas com deficiência, no mercado de trabalho, em países semiperiféricos. Para isso, utilizou-se a comparação entre dois países que ocupam a posição de semiperiferia no sistema mundo: Portugal e Brasil. O objetivo desta pesquisa consistiu em investigar as políticas públicas de inclusão no mercado de trabalho em Portugal e no Brasil, com a finalidade de realizar uma comparação entre ambos os países quanto a inclusão social das pessoas com deficiência. Tem-se como hipótese que, em ambos os países, o Estado transferiu efetivamente a responsabilidade da inclusão da pessoa com deficiência no mercado de trabalho à sociedade civil, ficando a ação estatal restrita à fiscalização. A metodologia empregada foi a qualitativa. Primeiramente, utilizou-se a análise documental e a partir disso foi realizada a comparação entre os países para ressaltar as diferenças ou semelhanças entre eles. A partir desta análise comparativa, foi possível verificar que, tanto Portugal como o Brasil, ainda prevalecem a concepção da deficiência como problema individual. Além disso, em ambos os países o Estado tem repassado à sociedade civil o papel de incluir as pessoas com deficiência no mercado de trabalho, cabendo ao Estado, via de regra, apenas a fiscalização da reserva de vagas, por parte das empresas, para as pessoas com deficiência.
\end{abstract}

Palavras-Chave: políticas públicas, inclusão, pessoas com deficiência, mercado de trabalho.

\section{Social well-being and public policies aimed at including people with disabilities in the labor market in Brazil and Portugal}

Abstract: The work sought to answer: How have public policies for the inclusion of people with disabilities in the labor market been developed in semi-peripheral countries? For that, we used the comparison between two countries that occupy the position of semiperiphery in the world system: Portugal and Brazil. The objective of this research was to investigate public policies for inclusion in the labor market in Portugal and Brazil, in order to make a comparison between both countries regarding the social inclusion of people with disabilities. It is hypothesized that in both countries the State effectively transferred the responsibility for including people with disabilities in the labor market to civil society, with state action being restricted to inspection. The methodology used was qualitative. First, documentary analysis was used and from that point on, the comparison between countries was made to highlight the differences or similarities between them. From this comparative analysis, it was possible to verify that, both Portugal and Brazil, the concept of disability as an individual problem still prevails. In addition, in both countries the State has transferred the role of including people with disabilities to the labor market to civil society, with the State, as a rule, only supervising the reservation of vacancies by companies for people with disabilities.

Keywords: public policies, inclusion, people with disabilities, labor market.

\footnotetext{
* Doutoranda em Ciência Política na Universidade Federal do Rio Grande do Sul (UFRGS), mestre em Direito e Justiça Social pela Universidade Federal de Rio Grande - FURG

** Mestranda em Direito e Justiça Social pela Universidade Federal do Rio Grande, especialista em Direito Civil e Processual Civil pela Universidade Estácio de Sá - CAMPUS SANTA MARIA

**** Possui Graduação em Direito pela Universidade Federal do Rio Grande (FURG), Mestrado e Doutorado em Educação Ambiental pela mesma Instituição de Ensino (PPGEA-FURG)

***** Doutora em Ciência Política pela Universidade Federal Fluminense - UFF (2019), Mestre em Ciência Política pela Universidade Federal de Pelotas-UFPEL (2015), Bacharel em Ciências Econômicas pela Universidade Federal do Rio Grande-FURG

****** Mestranda em Direito e Justiça Social pela Universidade Federal do Rio Grande. Graduação em Direito pela Faculdade Anhanguera de Rio Grande
} 
Campos Neutrais - Revista Latino-Americana de Relações Internacionais Vol. 2, No 1, Janeiro- Abril de 2020. Santa Vitória do Palmar - RS.

\section{Introdução}

Estima-se que as pessoas com deficiência representam cerca de $10 \%$ da população mundial (650 milhões de pessoas), um percentual expressivo. (UNRIC, 2015). Do total de pessoas com deficiência, cerca de $80 \%$ vivem em países considerados "emergentes". No Brasil, de acordo com os dados coletados pelo Instituto Brasileiro de Geografia e Estatística (IBGE), no censo de 2010, foram identificadas 45.606 .048 pessoas com deficiência, o que corresponde a cerca de 23,9\% da população. (OLIVEIRA, 2012).

Nos países mais desenvolvidos, de acordo com Guerra (2005), as pessoas com deficiência continuam a ser vítimas de exclusão social e a sofrer com as desigualdades sociais. Na União Europeia, quase 38 milhões de pessoas apresentam algum tipo de incapacidade. Ainda, segundo este autor, em Portugal, o número de pessoas que possuem alguma incapacidade é de, aproximadamente, um milhão de pessoas. Esse número é tanto mais preocupante, se tivermos em conta que as pessoas com deficiência apresentam, aqui, uma taxa de risco de pobreza 25\% superior às pessoas sem deficiência. (INE, 2013).

Ainda que seja um assunto de grande relevância para a sociedade e uma questão que envolve os direitos humanos, a análise das políticas públicas para pessoas com deficiência ainda é muito incipiente, dependendo dos contextos geográficos. Além disso, é recente a visão da deficiência como forma de opressão social, resultante da soma de fatores sociais e ambientais.

No que toca à questão da inclusão, esta pode ser pensada de várias formas, uma delas é através da inclusão no mercado de trabalho. Como afirmam Estanque e Costa (2014, p. 4) "é verdade que o trabalho se tornou um bem cada vez mais escasso, mas isso não só não lhe retirou importância, como até realçou o seu papel enquanto fator de afirmação da dignidade do trabalhador e da defesa dos direitos humanos".

Neste sentido, o trabalho deve ser visto como "parte de um resgate maior: o da cidadania. Com relação às pessoas com deficiência, estas passam a ter [e a realizar] [...] desejos, vontades, necessidades de consumo que, quando confinadas em casa, não existiam”. (GIL, 2002, p. 14). Identificando o quão importante é o trabalho na sociedade e seu papel altamente relevante na vida das pessoas com deficiência, a presente investigação buscou responder o seguinte questionamento: Como têm sido desenvolvidas as políticas públicas de inclusão das pessoas com deficiência, no mercado de trabalho, em países semiperiféricos? Para isso, será utilizada a comparação entre dois países, que ocupam a posição de semiperiferia no sistema mundo: Portugal e Brasil. 
Campos Neutrais - Revista Latino-Americana de Relações Internacionais Vol. 2, No 1, Janeiro- Abril de 2020. Santa Vitória do Palmar - RS.

O objetivo desta pesquisa é investigar as políticas públicas de inclusão no mercado de trabalho em Portugal e no Brasil, com a finalidade de realizar uma comparação entre ambos os países quanto a inclusão laboral das pessoas com deficiência. Tem-se, inicialmente, como hipótese, que, em ambos os países, o Estado transferiu a responsabilidade da inclusão da pessoa com deficiência, no mercado de trabalho à sociedade, ficando a ação estatal restrita à fiscalização. $O$ método selecionado para o desenvolvimento deste trabalho foi o qualitativo. Primeiramente, utilizou-se a análise documental e, a partir disso, foi realizada a comparação entre os países, para ressaltar as diferenças ou semelhanças entre eles.

$\mathrm{O}$ trabalho foi dividido em quatro partes. $\mathrm{O}$ primeiro tópico realiza o posicionamento do Brasil e de Portugal, no sistema mundo e a justificativa de seu enquadramento como países semiperiféricos. O segundo tópico traz a caracterização conceitual das políticas públicas e o enquadramento das pessoas com deficiência. A terceira parte trata das ações voltadas ao bem-estar social e da história dos direitos das pessoas com deficiência no Brasil e em Portugal. O último tópico apresenta o cenário, especificamente, das políticas voltadas à inclusão das pessoas com deficiência nos dois países, com a finalidade de identificar suas similaridades e diferenças.

\section{Por que Brasil e Portugal?}

A classificação do Sistema-mundo é uma teoria que busca:

compreender os processos fundamentais de estruturação econômica e social a partir de análises de grandes escalas espaciais e temporais. Neste sentido, a economia capitalista mundial é entendida como um todo integrado economicamente, baseada na divisão do trabalho". (REIS, 1993, p. 136).

O conceito de sistema-mundo foi cunhado por Immanuel Wallerstein, em sua obra intitulada "World Sistems Analysis" publicada em 1974. Segundo esse autor:

[...] a divisão do trabalho de uma economia-mundo capitalista divide a produção em produtos do centro e produtos periféricos [...], materializando-se, assim, como uma estrutura a nível mundial, que categoriza os países em três níveis: centro, periferia e semiperiferia [onde] a semiperiferia seria um conceito relacional. (WALLERSTEIN, 2004, p. 28).

Sobre a semiperiferia, Wallerstein (1979) afirma que ela abrange: 
Campos Neutrais - Revista Latino-Americana de Relações Internacionais Vol. 2, No 1, Janeiro- Abril de 2020. Santa Vitória do Palmar - RS.

[...] todos os Estados que desempenham um papel intermediário na economia mundial: grandes ao longo de pelo menos uma dimensão crucial (população, mão-de-obra qualificada, produção industrial total, renda per capita), tendem a produzir bens manufaturados para um Mercado interno e vizinhos mais fracos, mas ainda um exportador de produtos primários, desempenhando o papel de parceiro periférico para os países do núcleo e parceiro principal para alguns países periféricos. (WALLERSTEIN, 1979, p. 245-246).

Segundo Santos (1993, p. 23), esta posição intermediária faz com que um “determinado país atue como país periférico em relação a um país central e como país central em relação à periferia. [...] A natureza intermediária de uma determinada sociedade se traduz em características sociais que são específicas dessa sociedade". No caso brasileiro, a posição de semiperiferia pode ser justificada, conforme Ouriques (2016), em função do país ser:

[...] dotado de abundância de recursos naturais, grande contingente populacional, diversificação do parque industrial, e ainda uma enorme desigualdade de renda e social, o país apresenta características de Estado semiperiférico, pois possui em seu território um misto de atividades de núcleo orgânico e atividades periféricas. (OURIQUES, 2016, p. 6).

De acordo com Ouriques (2016), o Brasil apresenta diversos indicadores, em níveis intermediários, tais como os de saúde, rendimento e escolaridade, quando comparados a países centrais e/ou periféricos. Em relação a Portugal, Santos (1993) afirma que:

[...] em certos aspectos a sociedade Portuguesa se aproxima das características geralmente atribuídas aos países centrais, noutros parece mais próxima das características do terceiro mundo. Em termos de indicadores socioeconómicos, Portugal ocupa uma posição intermediária no sistema-mundial. (SANTOS, 1993, p. 21).

Outra questão importante é a jovem democracia de ambos. Em Portugal, o período ditatorial manteve-se entre 1926 e 1974 (ditadura mais longa da Europa), tendo somente sido derrubada por uma Revolução "sem sangue", em 25 de abril de 1974. (SANTOS, 1993, p. 19). No Brasil, a ditadura militar durou de 1964 até o ano de 1985. Dessa forma, estes países têm uma história recente, no que tange às políticas públicas, tendo em conta que esta é, segundo Di Giovanni (2009, p. 4-5), "uma forma contemporânea de exercício do poder nas sociedades democráticas". Além disso, a comparação com outros países permite auxiliar na identificação de falhas e no aproveitamento de ações, com impacto confirmado, encontrando alternativas realistas para o resgate da cidadania das pessoas com 
Campos Neutrais - Revista Latino-Americana de Relações Internacionais Vol. 2, No 1, Janeiro- Abril de 2020. Santa Vitória do Palmar - RS.

deficiência.

\section{O Cenário das Políticas Públicas}

As políticas públicas não apresentam conceituação única, sendo moldadas de acordo, tanto com sua utilização empírica quanto teórica (SOUZA, 2006), e:

[...] apesar de optar por abordagens diferentes, as definições de políticas públicas assumem, em geral, uma visão holística do tema, uma perspectiva de que o todo é mais importante de que a soma das partes e que indivíduos, instituições, interações, ideologia e interesses contam, mesmo que existam diferenças sobre a importância relativa desses fatores. (SOUZA, 2012, p. 69).

Um dos conceitos mais difundidos é o apresentado por Laswell (SOUZA, 2006, p. 26), onde "decisões e análises sobre política pública implicam responder às seguintes questões: quem ganha o quê, por quê e que diferença faz". Entretanto, o presente estudo será norteado pelo conceito, que apresenta política pública como sendo:

O campo do conhecimento que busca, ao mesmo tempo, "colocar o governo em ação" e/ou analisar essa ação [...] e, quando necessário, propor mudanças no rumo ou curso dessas ações". (SOUZA, 2006, p. 26).

As políticas públicas são elaboradas em um ambiente de conflito, caracterizado por "relações de poder, extremamente problemáticas, entre atores do Estado e da sociedade, entre agências intersetoriais, entre os poderes do Estado, entre o nível nacional e níveis subnacionais, entre comunidade política e burocracia". (RUA, 2010, p. 36). O Estado aqui é apresentado como "um sistema político - administrativo, cujas atividades se desenvolvem em diferentes níveis, envolvendo diferentes atores e quadros de regras". (RODRIGUES, 2014, p. 17).

A análise destas políticas é uma atividade política e social, que se desenrola através da junção de conhecimentos provenientes de diversas áreas de estudo, com o intuito de analisar e buscar a solução dos problemas apresentados pelas políticas. (BARDACH, 1989). Esse processo envolve uma grande quantidade de atividades, que estão relacionadas a apreciação das causas e consequências da ação do governo. (DAGNINO, 2004). Rua (1998) destaca que as políticas públicas:

[...] são uma das resultantes da atividade política: compreendem o 
Campos Neutrais - Revista Latino-Americana de Relações Internacionais Vol. 2, No 1, Janeiro- Abril de 2020. Santa Vitória do Palmar - RS.

conjunto das decisões e ações relativas à alocação imperativa de valores envolvendo bens públicos. (...) geralmente envolve mais do que uma decisão e requer diversas ações estrategicamente selecionadas para implementar as decisões tomadas. (RUA, 1998, p. 19).

Entretanto, é imprescindível lembrar que, para esta autora, as políticas públicas são "públicas" (não privadas ou apenas coletivas). Esta dimensão "é dada não pelo tamanho do agregado social sobre o qual incidem, mas pelo seu caráter 'imperativo'[...] são decisões e ações revestidas da autoridade soberana do poder público" (RUA, 1998, p. 2).

Para Di Giovanni (2009, p. 4-5), a política pública é "uma forma contemporânea de exercício do poder nas sociedades democráticas", sendo um espaço de relação entre o Estado e a Sociedade Civil que deve colocar em prática as plataformas eleitorais, através de ações que resolvam determinada situação social problemática. Esse autor acrescenta, ainda, a existência de alguma capacidade na formulação da agenda pública, ou seja:

[...] uma capacidade mínima de planificação consolidada nos aparelhos de Estado, seja do ponto de vista técnico de gestão, seja do ponto de vista político. Pressupõe-se, também, certa estruturação republicana da ordem política vigente: coexistência e independência de poderes e vigência de direitos de cidadania. (DI GIOVANNI, 2009, p. 5).

Os estudos sobre políticas públicas foram conduzidos, com base no pressuposto de que "em democracias estáveis, aquilo que o governo faz ou deixa de fazer é passível de ser formulado cientificamente e analisado por pesquisadores independentes". (SOUZA, 2006, p. 22). Tais estudos vêm buscando reduzir as dificuldades da implementação de novas práticas na gestão do governo, sendo necessária, para isso, a identificação dos fatores que influenciam no processo de decisão, formulação e implementação das políticas públicas.

As políticas públicas se apresentam como um instrumento valioso na mudança dos paradigmas e na garantia da universalização das políticas sociais, em todos os âmbitos, em especial, no respeito pelas diferenças. (SDH/PR e SNPDCP, 2011). Todavia, "para que as políticas se convertam em instrumentos efetivos de mudança, é necessário que sejam definidos mecanismos claros de monitorização, avaliação e fiscalização". (PORTUGAL, 2010, p. 284).

Neste sentido, o estudo das políticas públicas auxilia no reconhecimento da viabilidade das ações e dos projetos dos governos, além de perceber como o Estado visualiza e atende as demandas e reivindicações dos cidadãos, como é o caso das políticas voltadas às pessoas com deficiência. Tal análise possibilita um maior entendimento da 
Campos Neutrais - Revista Latino-Americana de Relações Internacionais Vol. 2, No 1, Janeiro- Abril de 2020. Santa Vitória do Palmar - RS.

situação desse segmento social, que é tão expressivo.

As políticas públicas podem ser classificadas de acordo com a sua natureza ou seu grau de intervenção. Em consonância com o afirmado anteriormente, podemos distinguir entre políticas "estruturais", que objetivam afetar relações como o rendimento e a propriedade; e políticas "conjunturais ou emergenciais" que visam abrandar situações problemáticas emergenciais, (TEIXEIRA, 2002). Ainda, é possível classificar as políticas de acordo com a abrangência dos seus resultados: as políticas "universais", que abrangem todos os indivíduos, sem distinção de grupos; as políticas "segmentais", quando direcionadas a determinados segmentos da população identificados, com base num determinado fator, como a idade e o gênero; e as políticas "fragmentadas", quando direcionadas a determinados grupos sociais. dentro dos diversos segmentos da população. (TEIXEIRA, 2002).

Theodore Lowi (SOUZA, 2006) desenvolveu uma importante tipologia de política pública, afirmando que esta pode assumir quatro formatos, tendo em conta os impactos nos beneficiários destas políticas: políticas distributivas, políticas constitutivas, políticas regulatórias e políticas redistributivas. As políticas distributivas correspondem às decisões que o governo toma, privilegiando determinados grupos sociais ou regiões, cujos impactos são individuais e não universais. As políticas regulatórias são formuladas com o intuito de criar normas, envolvendo burocracia e grupos de interesse. As políticas constitutivas lidam com procedimentos. (SOUZA, 2006). Já as políticas redistributivas caracterizam-se por atingirem um "maior número de pessoas e imporem perdas concretas e no curto prazo para certos grupos sociais, e ganhos incertos e futuro para outros; são, em geral, as políticas sociais". (SOUZA, 2006, p. 29).

As políticas públicas destinadas às pessoas com deficiência são essencialmente estruturais, segmentais e redistributivas, pois, como apresentado, se destinam a um determinado grupo social (no caso, as pessoas com deficiência) e buscam compensar as perdas concretas e possibilitar ganhos futuros, que seriam incertos, sem estas políticas.

\section{Políticas Públicas e Welfare State}

O Welfare State (Estado de Bem-Estar Social), é uma expressão inglesa, criada na década de 1940, para denominar a forma de organização do Estado como agente promotor de proteção social, com o objetivo de garantir padrões mínimos de vida à população. (NOGUEIRA, 2001). Os primeiros resquícios da política social que desencadeou a proteção social moderna se remetem ao final do século XIX, na Alemanha, mas foi após a 
Campos Neutrais - Revista Latino-Americana de Relações Internacionais Vol. 2, No 1, Janeiro- Abril de 2020. Santa Vitória do Palmar - RS.

Segunda Guerra Mundial, que eclodiu, nos países industrializados, a expansão dos serviços sociais, criando uma estrutura institucional de proteção para a superação dos efeitos danosos, causados pela economia capitalista. (NOGUEIRA, 2001).

O Welfare State ${ }^{1}$, pode ser entendido como:

[...] um conjunto de serviços e benefícios sociais de alcance universal promovidos pelo Estado com a finalidade de garantir uma certa "harmonia" entre o avanço das forças de mercado e uma relativa estabilidade social, suprindo a sociedade de benefícios sociais que significam segurança aos indivíduos para manterem um mínimo de base material e níveis de padrão de vida, que possam enfrentar os efeitos deletérios de uma estrutura de produção capitalista desenvolvida e excludente. (GOMES, 2006, p. 203).

O Welfare State é o resultado:

[...] de um compromisso, ou de um certo pacto teorizado no plano econômico de Keynes, entre o Estado, o capital e o trabalho, nos termos do qual os capitalistas renunciam a parte da sua autonomia e dos seus lucros (no curto prazo, não no médio prazo) e os trabalhadores a parte da sua reinvindicação (as que respeitam à subversão da sociedade capitalista e à sua substituição pela sociedade socialista). Esta dupla renúncia é gerida pelo Estado. (SANTOS e HESPANHA, 1987, p. 14).

Em Portugal, o Welfare State é denominado de Estado-providência.

\subsection{Welfare State e a evolução das ações públicas em relação aos direitos das pessoas com deficiência em Portugal}

Em Portugal, a Revolução de 1974 não acarretou somente a transição para a democracia, mas trouxe, consigo, entre outros elementos, o nascimento do EstadoProvidência. (SANTOS, 1993). Segundo Santos (1993, p. 44):

[...]não chegou a estabelecer-se nenhum pacto social e a hipertrofia da normatização estatal em detrimento da normatização contratual e cultural é [...] evidente nas políticas sociais", consequentemente "o Estado português não é um Estado-providência no sentido próprio do termo, embora em certos aspectos se aproxime dessa forma política". (SANTOS, 1993, p. 43).

Criou-se, segundo Santos (1993), um Semi-Estado-Providência, constituído

\footnotetext{
${ }^{1}$ Também serão utilizados os termos "Estado Providência" ou "Estado de Bem-Estar Social", como sinônimo de WelfareState durante o desenvolvimento do trabalho.
} 
Campos Neutrais - Revista Latino-Americana de Relações Internacionais Vol. 2, No 1, Janeiro- Abril de 2020. Santa Vitória do Palmar - RS.

tardiamente, após a Revolução de 1974, quando nos demais países europeus esta forma política já se encontrava em decadência. Esse atraso no desenvolvimento teve como resultado um Estado de Bem-Estar Social pouco eficiente, com uma baixa proteção e redistribuição social (SANTOS, 1991), contudo:

[...] no período imediatamente após Abril de 1974 começa a tornar-se significativa a responsabilização política do Estado, muito por pressão da sociedade civil emergente, com o objectivo de uma redistribuição mais igualitária e da garantia de um mínimo social de padrões nacionais de vida e proteção social. (HESPANHA et. al. 2000).

Nesse contexto de democratização, diversas foram as ações relacionadas à extensão de direitos às pessoas com deficiência e a ascensão das questões da deficiência, com caráter político. (FONTES, 2010). Em 14 de maio de 1974, foi fundada a Associação dos Deficientes das Forças Armadas - ADFA (ADFA, 2015), a primeira organização, após a Revolução de 25 de abril, a ser criada, tendo em conta que:

$\mathrm{O}$ regime ditatorial e o reduzido número de pessoas em unidades residenciais impediu a formação desta solidariedade que surgirá apenas entre os Deficientes das Forças Armadas precisamente em resultado da sua experiência coletiva. (FONTES, 2010, p. 93).

A força de mobilização dos Deficientes das Forças Armadas (DFA), através de manifestações, bloqueio de estradas e ações de lobbying (FONTES, 2016), fez com que, em janeiro de 1976, fosse publicado o Decreto-Lei $n^{\circ} 43 / 76$, reconhecendo "o direito à reparação material e moral que assiste aos deficientes das forças armadas e institui medidas e meios que concorram para a sua plena integração na sociedade”. (PORTUGAL, 1976). Estes direitos "foram posteriormente alargados a outras pessoas com deficiência (DecretoLei 143/78 de 12 de Junho de 1978; Decreto-Lei 255-A/82, de 30 de Junho de 1982; Decreto-Lei 239/80, de 10 de Julho de 1980)". (FONTES, 2016, p. 66).

Um grande avanço sobre as questões da deficiência foi sua inclusão na Constituição da República Portuguesa (CRP), aprovada em 1976, em seu Capítulo II:

1. Os cidadãos física ou mentalmente deficientes gozam plenamente dos direitos e estão sujeitos aos deveres consignados na Constituição, com ressalva do exercício ou do cumprimento daqueles para os quais se encontrem incapacitados.

2. O Estado obriga-se a realizar uma política nacional de prevenção e de tratamento, reabilitação e integração dos deficientes, a desenvolver uma pedagogia que sensibilize a sociedade quanto aos deveres de respeito e 
solidariedade para com eles e a assumir o encargo da efectiva realização dos seus direitos, sem prejuízo dos direitos e deveres dos pais ou tutores. (CRP, 1976, Art. 71º).

Em dezembro de 1979, foi instituído "um sistema mínimo (universal) de proteção social, abandonando o tradicional princípio de proteção social apenas aos beneficiários do regime contributivo". (PORTUGAL, 1979). Tal medida, com relação à prestação de segurança social, previa, entre outros benefícios a incorporação de pensão social, subsídio mensal para pessoas com deficiência menores e suplemento para "grandes inválidos" (HESPANHA et. al. 2000). Em maio de 1980, foi introduzido "o princípio da seletividade nas políticas sociais ao criar dois regimes distintos de proteção social” (FONTES, 2016, p. 63), retrocedendo face aos direitos "universalistas" de proteção social, instituídos no Decreto-lei 513-L/79.

Também, no início da década de 1980, foi criado um subsídio mensal vitalício para as pessoas com deficiência, com mais de 24 anos. (PORTUGAL, 1980). Em 1982, foi adicionado o número três, no artigo $71^{\circ}$ da Constituição da República Portuguesa, com a redação de que "o Estado apoia as associações de deficientes" 2 ". (CRP, Art. 71º). Diversos outros Decretos-Lei foram publicados durante todo período, entre eles: avaliação de incapacidade das pessoas com deficiência (PORTUGAL, 1996), sistema de atestados médicos de incapacidade multiuso (PORTUGAL, 1997), Lei de bases da prevenção e reabilitação e integração das pessoas com deficiência (PORTUGAL, 1998) e acompanhamento familiar de deficientes hospitalizados. (PORTUGAL, 1997).

A “característica mais marcante das políticas de deficiência, desde 1974, tem sido a ausência de uma estratégia global. Com efeito, as políticas de deficiência, em Portugal, têm-se centrado em aspectos particulares da deficiência" (FONTE, 2016, p. 67). A publicação da Lei 38/2004 visava realizar:

[...] uma política global, integrada e transversal de prevenção, habilitação, reabilitação e participação da pessoa com deficiência, através, nomeadamente, da:

a) Promoção da igualdade de oportunidades, no sentido de que a pessoa com deficiência disponha de condições que permitam a plena participação na sociedade;

b) Promoção de oportunidades de educação, formação e trabalho ao longo da vida;

c) Promoção do acesso a serviços de apoio;

d) Promoção de uma sociedade para todos através da eliminação de

\footnotetext{
2 “Em 1997 o uso de 'deficientes' foi substituído pelo de 'cidadãos portadores de deficiência”" (FONTES, 2016, p. 60).
} 
Campos Neutrais - Revista Latino-Americana de Relações Internacionais Vol. 2, No 1, Janeiro- Abril de 2020. Santa Vitória do Palmar - RS.

barreiras e da adopção de medidas que visem a plena participação da pessoa com deficiência. (PORTUGAL, 2004).

Nesse sentido, a referida lei implantou o conceito de pessoa com deficiência, nos moldes biopsicossocial:

[...] pessoa com deficiência [é] aquela que, por motivo de perda ou anomalia, congénita ou adquirida, de funções ou de estruturas do corpo, incluindo as funções psicológicas, apresente dificuldades específicas susceptíveis de, em conjugação com os fatores do meio, lhe limitar ou dificultar a atividade e a participação em condições de igualdade com as demais pessoas. (PORTUGAL, 2004).

Em 2006, ocorreu a publicação da Lei 46/2006, conhecida como "1 Plano de Ação para a Integração das Pessoas com Deficiências ou Incapacidade - 2006/2009” estendido até 2015. Tal instrumento "concentra e organiza de forma coerente o essencial das diversas vertentes da política de deficiência e que a projeta num horizonte de médio prazo através da definição das suas coordenadas fundamentais" (SEAR e SNRIPCD, 2006, p. 7).

Esse plano foi apresentado em quatro eixos fundamentais de intervenção estatal, conectados entre si: acessibilidades e informação, educação, qualificação e promoção da inclusão laboral, habilitar e assegurar condições de vida dignas, investigação e conhecimento. Contudo, se faz necessária a identificação de quanto desse plano foi realmente colocado em prática e se teve impacto na vida das pessoas com deficiência.

É claro que ainda se faz necessária a ampliação dos direitos e da forma com que as pessoas com deficiência são percebidas pela sociedade em Portugal. Essas questões não anulam os avanços das políticas para pessoas com deficiência, após 1974, mas é clara a falta de uma política global, detendo-se, geralmente, a aspectos particulares de deficiência "sendo apenas recente a inclusão de perspectivas mais abrangentes e integradas. Estas políticas conduziram assim a uma legislação de forte pendor particularista, em torno de temas específicos”. (FONTES, 2009, p. 83).

\subsection{Welfare State e a evolução das ações públicas em relação aos direitos das pessoas com deficiência no Brasil}

No Brasil não há consenso quanto a existência do Welfare State. Segundo Gomes (2006, p. 221), "talvez seja mais coerente considerar que, durante todo o processo histórico de formação e estruturação das formas do Estado moderno no Brasil, não se tenha implementado mais do que apenas algumas políticas de bem-estar social". 
Campos Neutrais - Revista Latino-Americana de Relações Internacionais Vol. 2, No 1, Janeiro- Abril de 2020. Santa Vitória do Palmar - RS.

Até a década de 1970, de acordo com Lanna Jr. (2010), as pessoas com deficiência não possuíam espaço para participarem nas decisões referentes à sua própria vida, dependendo, muitas vezes, da caridade e da compaixão alheia e as ações governamentais se resumiam a programas de características assistencialistas. Paralelamente as poucas ou quase inexistentes iniciativas do Estado, no final da década de 1970, ocorreram diversas mobilizações, organizadas por pessoas com deficiência que tiveram como consequência a criação do "Movimento Político das Pessoas com Deficiência", que as tornou agentes políticos ativos e protagonistas de suas lutas e demandas. (LANNA JR, 2010). Esse movimento tinha como objetivo reivindicar e lutar pelos direitos deste grupo, por uma igualdade de oportunidade, e pelo direito a ocuparem um espaço na arena pública, assumindo, assim, o papel de agentes políticos, no momento de enfraquecimento do regime militar. (LANNA JR, 2010).

O regime militar se instaurou em 31 de março de 1964 e se manteve até 15 de janeiro de 1985. Ele representou a ascensão de uma força autoritária político-institucional, que materializou "a repressão, o cerceamento da liberdade de expressão, o controle e a desarticulação de todos os mecanismos tradicionais de representação do país" (COSTA, 1988, p. 4). Entretanto, com o enfraquecimento do regime militar e início do processo de abertura política, que se deu de forma "lenta, gradual e segura", os movimentos sociais, "antes silenciados pelo autoritarismo, ressurgiram como forças políticas. Vários setores da sociedade gritaram com sede e com fome de participação: negros, mulheres, índios, trabalhadores, sem-teto, sem-terra e, também, as pessoas com deficiência”. (LANNA JR, 2010, p. 34).

Um exemplo da luta das pessoas com deficiência, nesse período, foi a "Coalisão Pró-Federação Nacional de Entidades de Pessoas Deficientes”, criada em 1979. Esse movimento tinha como objetivo "organizar uma federação nacional de entidades de pessoas com deficiência que se ocupasse de articular o movimento nacionalmente" (LANNA JR, 2010, p. 34), além de traçar ações na luta por direitos das pessoas com deficiência para participarem no mercado de trabalho, ensino e em todos os setores da sociedade de forma autônoma (LANNA JR, 2010), sendo politicamente contrário "ao caráter de caridade que marcou historicamente as ações voltadas para esse público" LANNA JR, 2010, p. 35).A própria sociedade civil realizou diversas iniciativas, entre elas: 
Campos Neutrais - Revista Latino-Americana de Relações Internacionais Vol. 2, No 1, Janeiro- Abril de 2020. Santa Vitória do Palmar - RS.

deficiência intelectual (atendimento educacional, médico, psicológico e de apoio à família); e os centros de reabilitação, como a Associação Brasileira Beneficente de Reabilitação (ABBR) e a Associação de Assistência à Criança Defeituosa - (AACD), dirigidos, primeiramente, às vítimas da epidemia de poliomielite. (LANNA JR, 2010, p. 15).

A APAE foi fundada em 1954, no estado do Rio de Janeiro, sendo constituída por:

[...] pais e amigos de uma comunidade significativa [...] de pessoas com deficiência, contando para tanto com a colaboração da sociedade em geral, do comercio, da indústria, dos profissionais liberais, dos políticos, enfim de todos quantos acreditam, apostam e lutam pela causa da pessoa com deficiência. (APAE, 2008, p. 2).

Esta instituição é o "maior movimento filantrópico do Brasil e do mundo, na sua área de atuação". (APAE, 2008, p. 2). A mobilização deste e de outros movimentos possibilitou uma das primeiras conquistas com relação à legislação, que foi o reconhecimento por parte do Estado de suas responsabilidades para com essas pessoas, com a proclamação da Constituição Federal, de 1988, que apresentava diversos capítulos sobre os direitos das pessoas com deficiência, tais como:

[...] Artigo 23 - É competência comum da União, dos Estados, do Distrito Federal e dos Municípios: [...]

II - cuidar da saúde e assistência pública, da proteção e garantia das pessoas com deficiência $[\ldots]$

Artigo 24 - Compete à União, aos Estados e ao Distrito Federal legislar concorrentemente sobre: [...]

XIV - proteção e integração social das pessoas com deficiência (BRASIL, 1988, Art. 23 - 24).

Em seu Artigo 203, a Constituição Federal institui a assistência social às pessoas tornadas vulneráveis socioeconomicamente pela sociedade, sem a necessidade de contribuição à seguridade social, incluindo as pessoas com deficiência:

[...] a assistência social será prestada a quem dela necessitar, independentemente de contribuição à seguridade social, e tem por objetivos: [...]

IV - A habilitação e reabilitação das pessoas com deficiência e a promoção de sua integração à vida comunitária;

$\mathrm{V}$ - A garantia de um salário mínimo de benefício mensal à pessoa com deficiência e ao idoso que comprovem não possuir meios de prover à própria manutenção ou de tê-la provida por sua família, conforme dispuser a lei. (BRASIL, 1988, Art. 203). 
Campos Neutrais - Revista Latino-Americana de Relações Internacionais Vol. 2, No 1, Janeiro- Abril de 2020. Santa Vitória do Palmar - RS.

Em 1988, foi fundado, no país, o primeiro Centro de Vida Independente (CVI), no Rio de Janeiro. O CVI-Rio realiza a prestação de serviços:

[...] na área da deficiência, na orientação e informação de [...] [pessoas com deficiência] de todas as faixas etárias, além de familiares, profissionais, estudantes e demais interessados. Atua também, oferecendo assessoria, consultoria e desenvolvimento de projetos e programas especiais. (ABBR, 2004, p. 1).

Em 24 de julho de 1991, foi regulamentada, no Brasil, a Lei № 8.213, que "dispõe sobre os Planos de Benefícios da Previdência Social" e que, em seu artigo 93, estabeleceu cotas para a admissão de pessoas com deficiência nas empresas:

[...] a empresa com 100 (cem) ou mais empregados está obrigada a preencher de $2 \%$ (dois por cento) a $5 \%$ (cinco por cento) dos seus cargos com beneficiários reabilitados ou pessoas portadoras de deficiência, habilitadas, na seguinte proporção:

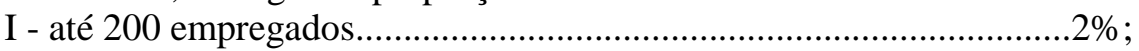

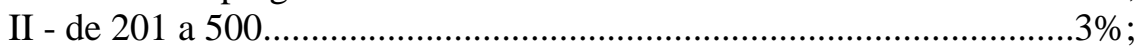

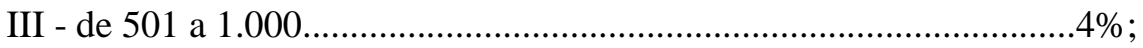

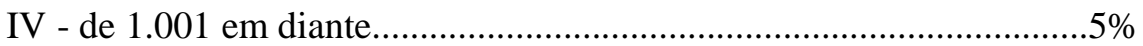

(BRASIL, 1991, Art. 93).

Nesse mesmo ano, entrou em vigor a Lei 8.742/93 que "dispõe sobre a organização da Assistência Social” e que garante o Benefício de Prestação Continuada (BPC) às pessoas com deficiência, que não possuem condições econômicas para manter as suas necessidades básicas, questão constante no Artigo 203, da CF/1988. (BRASIL, 1993). Posteriormente, no sentido de efetivar a inclusão e a garantia de direitos das pessoas com deficiência, foi publicado o Decreto $\mathrm{n}^{\circ}$ 3.298, de 20 de dezembro de 1999, regulamentando a Lei $\mathrm{n}^{\mathrm{0}} 7.853$, de 24 de outubro de 1989. Esse dispõe sobre a Política Nacional para a Integração da Pessoa Portadora de Deficiência que consolidou as normas de proteção. Em seu artigo $2^{\circ}$, atribui ao poder público (BRASIL, 1999):

[...] assegurar à pessoa [...] [com] deficiência o pleno exercício de seus direitos básicos, inclusive dos direitos à educação, à saúde, ao trabalho, ao desporto, ao turismo, ao lazer, à previdência social, à assistência social, ao transporte, à edificação pública, à habitação, à cultura, ao amparo à infância e à maternidade, e de outros que, decorrentes da Constituição e das leis, propiciem seu bem-estar pessoal, social e econômico. (BRASIL, 1999, Art. $2^{\circ}$ ).

Em 2008, foi incorporada, na legislação brasileira, a Convenção sobre os Direitos 
Campos Neutrais - Revista Latino-Americana de Relações Internacionais Vol. 2, $\mathrm{N}^{\mathrm{O}}$ 1, Janeiro- Abril de 2020. Santa Vitória do Palmar - RS.

das Pessoas com Deficiência (CDPCD), através do Decreto Legislativo ${ }^{\circ} 186$, de 9 de julho de 2008, objetivando garantir a melhora da qualidade de vida e a inclusão das pessoas com deficiência. (BRASIL, 2008). Apesar dos consideráveis avanços na busca pela inclusão, continuou sem reconhecimento, por parte da sociedade, a possibilidade de uma vida independente às pessoas com deficiência.

Foi aprovada, em 2015, a Lei Brasileira de Inclusão $\mathrm{n}^{\circ} 13.146$ (também denominado Estatuto da Pessoa com Deficiência) entrando em vigor em 5 de janeiro de 2016. Esta lei é "destinada a assegurar e a promover, em condições de igualdade, o exercício dos direitos e das liberdades fundamentais por pessoa com deficiência, visando à sua inclusão social e cidadania". (BRASIL, 2015, Art. $1^{\circ}$ ). É importante lembrar que esta lei é o resultado de um longo processo negocial, que se prolongou por cerca de 15 anos e que contemplou "1500 encontros: audiências públicas, seminários, consultas, conferências nacionais e regionais, com ampla participação de entidades, e do movimento de pessoas com deficiência”. (SENADO FEDERAL, 2015, p. 10).

De acordo com Lanna Jr. (2010, p. 16), no Brasil, o movimento de pessoas com deficiência tem buscado "refinar conceitos e mudar paradigmas, criando uma base sólida para a construção de uma nova perspectiva sobre a deficiência". As políticas públicas continuam, contudo, desligadas das reais necessidades das pessoas com deficiência, conforme se refere Araújo (2013, [s.p.]) "há tentativas, nas três esferas de governo, de se avançar no tema, mas são incipientes porque ainda não há no Brasil uma cultura da política pública efetivamente trabalhada para as dificuldades da vida diária". Não obstante, a legislação brasileira, na área, ter sido "considerada uma das mais inclusivas das Américas é, no entanto, a menos respeitada”. (D’AMARAL, 2015, [s.p.]). Isso faz com que as pessoas com deficiência continuem a viver uma realidade cercada por dificuldades e discriminação.

\section{Tópicos sobre inclusão no mercado de trabalho das pessoas com deficiência, em}

\section{Portugal e no Brasil}

O diálogo sobre a inclusão das pessoas com deficiência, no mercado de trabalho tem sido recorrente, principalmente a partir da década de 1960 (BARNES e MERCER, 2010). Mas, também, é evidente que a configuração atual do trabalho é opressiva, não dando espaço a estes sujeitos, muito em razão de não atenderem às expectativas impostas pelos empregadores, que não levam em conta que a própria configuração do trabalho é excludente. (DRAKE, 1999). 
Campos Neutrais - Revista Latino-Americana de Relações Internacionais Vol. 2, No 1, Janeiro- Abril de 2020. Santa Vitória do Palmar - RS.

Segundo Bates, Goodley e Runswick-Cole (2017), as sociedades capitalistas têm tido como regra a institucionalização das pessoas com deficiência, tornando-as objeto de estudo, de reabilitação e adequação à sociedade e não agentes ativos no mercado de trabalho. Esta questão é extremamente problemática, mas tem a sua intensidade amplificada, quando se verifica o trabalho, para além da remuneração, sendo elementochave na construção da identidade e sentimento de pertença social (DRAKE, 1999) uma vez que o trabalho "constrói relacionamentos, permite a participação na comunidade e promove autoidentidades positivas”. (BATES, GOODLEY e RUNSWICK-COLE, 2017). Porém, existe o outro lado, ou seja, "experiências de discriminação - e incidentes de marginalização em relação a força de trabalho - são profundamente inquietantes". (BATES, GOODLEY e RUNSWICK-COLE, 2017, p. 161).

A igualdade de oportunidades das pessoas com deficiência é a "pedra de toque" dos discursos internacionais, como pode ser observado na Convenção dos Direitos das Pessoas com Deficiência. Todavia, como colocam Goodley, Lawthom e Runswick-Cole (2014), o que, de fato, tem ocorrido é que a percepção social de que algumas pessoas são mais "iguais" do que outras. Na questão do mercado de trabalho, para pessoas com deficiência isso tem sido muito reproduzido, emergindo a questão da precariedade:

[...] condição politicamente induzida em que certas populações sofrem com a queda nas redes sociais e econômicas de apoio e se tornam diferentemente expostas à lesão, à violência e à morte. Tais populações estão em risco elevado de doença, pobreza, fome, deslocamentos e de exposição à violência sem proteção. (BUTLER, 2009, p. ii).

Goodley, Lawthom eRunswick-Cole (2014, p. 982) argumentam que:

[...] é absolutamente essencial que consideremos as formas como a pobreza e a deficiência estão [...] sendo unidas como categorias inseparáveis", excluindo as pessoas com deficiência que quando conseguem se incluir no mercado de trabalho isso acontece através de empregos precários. (GOODLEY, LAWTHOM e RUNSWICK-COLE, 2014, p. 982).

E essa situação, em grande parte, é consequência de uma formação educacional mais "pobre" das pessoas com deficiência, deixando a escola mais cedo e com uma qualificação inferior, quando comparada às pessoas sem deficiência. (DRAKE, 1999).

\subsection{Ações do Estado português}

Em Portugal, no ano de 2006, foi publicada a Lei 46/2006, que institui o $1^{\circ}$ Plano 
Campos Neutrais - Revista Latino-Americana de Relações Internacionais Vol. 2, No 1, Janeiro- Abril de 2020. Santa Vitória do Palmar - RS.

de Ação para a Integração das Pessoas com Deficiências ou Incapacidade, como já foi apresentado anteriormente. Este Plano foi definido, inicialmente, para o período 2006 2009, tendo sido, posteriormente, estendido até 2015. A questão da qualificação, formação e emprego das pessoas com deficiência ou incapacidade faziam parte dos objetivos do plano (PAIPDI, 2006) sendo que "a qualificação e o emprego" foram integrados em uma única estratégia, em harmonia com o especificado no Programa Nacional de Ação para o Crescimento e Emprego ${ }^{3}$ e no Plano Nacional de Emprego ${ }^{4}$.

Com relação à avaliação, à orientação profissional, à formação profissional e à readaptação ao trabalho, as seguintes instituições ficaram responsáveis: o Instituto do Emprego e Formação Profissional (IEFP), a Rede de Centros de Reabilitação Profissional de entidades privadas da área da deficiência (apoiadas pelo IEFP), o Centro de Reabilitação Profissional de Gestão Directa - Alcoitão; os Centros de Reabilitação Profissional de Gestão Participada - CEFPI e CRPG; as Empresas e os Centros de Emprego Protegido. (PAIPDI, 2006).

Tal como apresentado por Fontes (2016), o PAIPDI sofreu duras críticas das organizações de deficiência quanto à sua elaboração, principalmente por não ter havido a preocupação de ouvir as pessoas com deficiência. Sua abordagem não foi construída sobre as bases da sociedade deficientizadora, mantendo o caráter essencialmente médico, buscando, assim, a adaptação da pessoa com deficiência à sociedade. (FONTES, 2016). Como resultado, o PAIPDI não teve a implementação esperada e nem o impacto esperado na vida e na realidade das pessoas com deficiência em Portugal. (FONTES, 2016).

Ainda sobre a ótica da inclusão da pessoa com deficiência, no mercado de trabalho, no ano de 2009, foi publicado o Decreto-Lei $n^{\circ}$ 290/2009, que instituiu o Programa de Emprego e Apoio à Qualificação das Pessoas com Deficiências e Incapacidades que dita as bases para a concessão de apoio, no âmbito técnico e financeiro, para a elaboração de políticas voltadas ao emprego e a qualificação das pessoas com deficiência.

O Decreto-Lei 290/2009 tem por objetivos:

1- $\mathrm{O}$ apoio à qualificação das pessoas com deficiências e incapacidades é realizado através de acções de formação, inicial e contínua.

2- A formação profissional visa dotar as pessoas com deficiências e

\footnotetext{
3 Tem por objetivo "executar políticas de emprego para atingir o pleno emprego, melhorar a qualidade e a produtividade do trabalho e reforçar a coesão social e territorial.

${ }^{4}$ Cf. IFDR (s/p) "Este Programa enquadra os diversos programas e planos de ação com incidência no crescimento e emprego, nomeadamente o PEC, o Plano tecnológico e o Plano Nacional de Emprego. URA:< http://www.ifdr.pt/content.aspx?menuid=202\&eid=942>
} 
Campos Neutrais - Revista Latino-Americana de Relações Internacionais Vol. 2, No 1, Janeiro- Abril de 2020. Santa Vitória do Palmar - RS.

incapacidades dos conhecimentos e competências necessárias à obtenção de uma qualificação que lhes permita exercer uma actividade no mercado de trabalho, manter o emprego e progredir profissionalmente de forma sustentada.

3- A formação inicial destina-se às pessoas com deficiências e incapacidades que pretendem ingressar ou reingressar no mercado de trabalho e não dispõem de uma certificação escolar e profissional compatível com o exercício de uma profissão ou ocupação de um posto de trabalho.

4- A formação contínua destina-se às pessoas com deficiências e incapacidades empregadas ou desempregadas que pretendem melhorar as respectivas competências e qualificações visando a manutenção do emprego, progressão na carreira, reingresso no mercado de trabalho ou reconversão profissional, ajustando as suas qualificações às necessidades das empresas e do mercado de trabalho. (PORTUGAL, 2009).

Esse Decreto-Lei, ainda, estabelece o apoio para a qualificação e formação profissional, a isenção e redução de contribuições para a segurança social, adaptação da estrutura arquitetônica dos ambientes laborais, a colocação e acompanhamento pós colocação no mercado de trabalho. (PORTUGAL, 2009). Esse Decreto-Lei tem como público-alvo pessoas com idades iguais ou superiores a 15 anos, pessoas empregadas ou desempregadas, que tenham interesse em ampliar a sua qualificação, e pessoas sem as qualificações necessárias para desempenhar uma atividade laboral.

Uma questão muito importante é o apoio governamental para à adaptação dos postos de trabalho nas empresas que contratarem pessoas com deficiência, desempregadas ou à procura do primeiro emprego. Contudo, esse Decreto-Lei exclui o benefício, quando as adaptações forem necessárias para as pessoas com deficiência, cuja incapacidade tenha decorrido de acidentes de trabalho, na própria empresa, onde este fato ocorreu. (PORTUGAL, 2009).

No contexto do trabalho apoiado, integram-se a realização de estágios de inclusão e de contratos emprego-inclusão para pessoas com deficiências e incapacidades, centros de emprego protegido e contratos de emprego apoiado em entidades empregadoras, reconfigurando-se ainda o prémio de mérito. (PORTUGAL, 2009).

Embora existam avanços nas políticas públicas, é fato que, por suas características quanto à formulação e formas de implementação, até agora, não foi possível a quebra das barreiras "que impedem a integração e a participação das pessoas com deficiência na sociedade portuguesa e de quebrar o ciclo vicioso existente, qual seja, deficiência, pobreza e exclusão social.” (FONTE, 2016, p. 73). 
Campos Neutrais - Revista Latino-Americana de Relações Internacionais Vol. 2, No 1, Janeiro- Abril de 2020. Santa Vitória do Palmar - RS.

\subsection{Ações do Estado Brasileiro}

O Brasil tem realizado vários avanços, principalmente no ordenamento jurídico, em relação à inclusão social da pessoa com deficiência e sua inclusão no mercado de trabalho (SILVA, PRAIS e SILVEIRA, 2015). Um exemplo disso é a lei que ampara o emprego da pessoa com deficiência, através da Lei $\mathrm{n}^{\circ}$ 8.213/91, conhecida como lei de cotas (apresentada anteriormente) que obriga as empresas, com mais de 100 funcionários $^{5}$, a reservarem um percentual de vagas às pessoas com deficiência. (OLIVEIRA, [s.d.]). Contudo, o mercado de trabalho está longe de ser inclusivo, pois mesmo existindo vagas, estas não são preenchidas e o não cumprimento dessa lei, pelos empregadores, é justificada pela falta de mão-de-obra qualificada. (SILVA, PRAIS e SILVEIRA, 2015).

Nesta questão sobre a falta de qualificação profissional, é importante frisar que a educação inclusiva está diretamente ligada à inclusão laboral, ou seja:

[...] a educação inclusiva permite, desde a infância, o convívio entre as pessoas com deficiência e as demais. Isto restringe o preconceito e a discriminação e favorece a inclusão. A educação inclusiva também estimula a pessoa com deficiência a lidar com outros indivíduos, aprimorando a relação que ela estabelecerá com a sociedade. No entanto, existem poucos educadores capazes de lidar com as particularidades dessas pessoas, o que prejudica a formação e, consequentemente, a inclusão laboral. (SILVA, PRAIS e SILVEIRA, 2015, p. 2552).

Em junho de 2015, entrou em vigor a Lei 13.146/2015 denominada Estatuto da Pessoa com Deficiência, que apresenta, em seu Capítulo VI, dos artigos 34 a 38, as disposições gerais do direito ao trabalho. Este Estatuto contém desde a obrigatoriedade das empresas de direito público e privado, de garantir um ambiente acessível às pessoas com deficiência, até ao direito à igualdade de oportunidade, e vedar qualquer tipo de discriminação, dentro do ambiente de trabalho. (SENADO FEDERAL, 2015). Este Estatuto também aborda, em seu artigo 35, que "é finalidade primordial das políticas públicas de trabalho e emprego promover e garantir condições de acesso e de permanência da pessoa com deficiência no campo de trabalho”. (SENADO FEDERAL, 2015, p. 24).

O Brasil, no âmbito das políticas públicas, mesmo antes do Estatuto da Pessoa com Deficiência ser publicado, já implementava o Plano Nacional dos Direitos da Pessoa com Deficiência - Viver sem Limite, instituído em 2011, pelo decreto 7.612/2011, que visa implementar" os apoios necessários ao pleno e efetivo exercício da capacidade legal por

\footnotetext{
5 "Proporções que variam de acordo com o número de empregados: de 100 a 200, a reserva legal é de $2 \%$; de 201 a 500, de 3\%; de 501 a 1.000, de 4\%, e acima de 1.001, de 5\%" (OLIVEIRA, [s.d.]).
} 
Campos Neutrais - Revista Latino-Americana de Relações Internacionais Vol. 2, No 1, Janeiro- Abril de 2020. Santa Vitória do Palmar - RS.

todas as pessoas com deficiência”. (SEDPD, s/d). Este plano é executado pelo Governo Federal, em parceria com o Ministérios do Desenvolvimento Social e Combate à Fome (MDS), Ministério da Educação (MEC), o Ministério do Trabalho e Emprego (MTE), em conjunto com a Secretaria de Direitos Humanos da Presidência da República (SDH/PR). (MDSCF, SNAS, DBA, 2013).

O "Viver Bem" apresenta, como um de seus pontos estratégicos, o ensino profissionalizante, utilizando-se do Programa Nacional de Acesso ao Ensino Técnico e Emprego (PRONATEC), através da bolsa-formação para ministrar os cursos técnicos de nível médio, além da formação inicial e continuada (Cursos de qualificação profissional). A realização destes cursos ficou a cargo das instituições da Rede Federal de Educação Profissional e Tecnológica (Institutos Federais, Escolas técnicas que tenham vínculo com as universidades), serviços nacionais de aprendizagem (Serviço Nacional de Aprendizagem Industrial (SENAI), Serviço Nacional de Aprendizagem Comercial (SENAC), Serviço Nacional de aprendizagem do Transporte (SENAT) e Serviço Nacional de Aprendizagem Rural (SENAR). (SDH/PR e SNPD, 2013, p. 22).

Outro ponto estratégico do "Viver sem Limite" é o Programa Benefício de Prestação Continuada Trabalho, destinado às pessoas, da faixa etária entre 16 e 45 anos, que buscam uma qualificação, a inclusão no mercado de trabalho e estão cadastrados no Benefício de Prestação Continuada (BPC). (SDH/PR e SNPD, 2013):

[...] benefício este concedido às pessoas com deficiência [...], cuja unidade familiar ao qual pertençam não consiga promover suas necessidades básicas de sobrevivência, sendo que essa assistência é concedida independente de adesão prévia ao regime previdenciário oficial (Instituto Nacional do Seguro Social - INSS). (BRASIL, 1993).

No momento em que a pessoa com deficiência é contratada por uma empresa, o BPC é suspenso, mas um grande avanço é a possibilidade de retorno do benefício, caso o beneficiário perca o emprego. (SDH/PR e SNPD, 2013, p. 38). Isso possibilitou uma maior tranquilidade para as pessoas com deficiência, pois, anteriormente, retornar ao benefício, quando da perda do emprego, era um processo muito burocrático, havendo a possibilidade do BPC ser negado pelo INSS.

A partir das ações do governo federal, é possível perceber a forte presença de um entendimento médico da deficiência, embora algumas ações já estejam sendo orientadas na direção da percepção da deficiência, como opressão social. 
Campos Neutrais - Revista Latino-Americana de Relações Internacionais Vol. 2, No 1, Janeiro- Abril de 2020. Santa Vitória do Palmar - RS.

\section{Considerações Finais}

Ao longo desta investigação, buscou-se responder a problemática: como têm sido desenvolvidas as políticas públicas de inclusão das pessoas com deficiência, no mercado de trabalho, em países semiperiféricos? Para tanto, foi realizada a comparação entre Brasil e Portugal, tendo em conta suas posições semiperiféricas, dentro da classificação do Sistema-mundo. A partir da comparação, foi possível verificar que, em ambos os países, ainda é muito forte a concepção da deficiência, como problema individual. Isso acarreta ações governamentais pouco efetivas à inclusão no mercado de trabalho. As ações ainda têm buscado adaptar, habilitar e reabilitar a pessoa com deficiência para o ambiente laboral, quando a preocupação deveria ser procurar alternativas para a criação de ambientes com desenho universal acessíveis a todos, independentemente de sua condição ou incapacidade.

Com relação à hipótese inicial da investigação de que ambos os Estados repassaram sua responsabilidade à sociedade na inclusão econômica através do mercado de trabalho, ela foi comprovada, em partes, tendo em vista a identificação de posturas diferente no Brasil e em Portugal. No Brasil, ao que tudo indica, o Estado transferiu a sua responsabilidade, em grande parte, à sociedade civil e às empresas, legislando de forma que os custos monetários para a adaptação dos ambientes fiquem a cargo destes. A Lei de cotas é um exemplo disso, por meio da qual foi estipulada uma reserva de vagas às pessoas com deficiência, contudo, o Estado participa, na área fiscalizatória, sem auxiliar ou subsidiar as adaptações necessárias à inclusão das pessoas com deficiência, no ambiente de trabalho. A profissionalização também é insuficiente, já que as ações formuladas são para “inglês ver”, visto que, na maioria das vezes, não há preocupação com a sua implementação e efetividade.

Em Portugal, mesmo que se perceba um distanciamento entre as ações do governo e as reinvindicações das pessoas com deficiências, as ações são formuladas sem ouvir as demandas das pessoas com deficiência, não dando voz e ouvir aos grandes interessados nas decisões. Contudo, se comparado ao Brasil, se pode observar avanços, tendo em conta que, no Estado português, foram criados subsídios técnicos e financeiros às empresas, o que incentivam a adaptação do local de trabalho, criando lugares com desenho universal e, não somente, fiscalizando se as empresas cumprem com a legislação.

No entanto, a elaboração das políticas, por si só, não consegue dar a dimensão do quanto essas ações realmente impactam na vida das pessoas com deficiência. A avaliação de como as políticas estão sendo implementadas é de suma importância para dar conta de 
Campos Neutrais - Revista Latino-Americana de Relações Internacionais Vol. 2, No 1, Janeiro- Abril de 2020. Santa Vitória do Palmar - RS.

como está ocorrendo (e se está ocorrendo) uma mudança na visão da sociedade, encarando como reinvindicação de direitos e não de caridade ou compaixão.

\section{Bibliografia}

ABBR. Associação Brasileira de Beneficente de Reabilitação. Rio de Janeiro: berço de grandes trabalhos realizados para pessoas com deficiência. Revista Nacional de Reabilitação. Ano VII- ${ }^{\circ}$ 39, jul./ago. 2004. URA: 〈https://www.abbr.org.br/imprensa/revistanacional.htm〉.

ADFA - Associação dos Deficientes das Forças Armadas. Estatutos da ADFA. 2015. URL: <http://www2.adfa-portugal.com/adfapor/pdf/Estatutos\%20da\%20ADFA.pdf >

APAE - Associação de Pais e Amigos do Excepcionais. Um Pouco da História do Movimento das APAEs. 2008. URL: 〈http://novosite.apaebrasil.org.br/uploads/historico_10.12.2008\%20(1).pdf>

BARDACH, E. Los ocho passos para el análisis de políticas públicas: um manual para la práctica. (Tradução: MACHADO, D. G). Centro de Investigación y Docência Econômicas. 1989. Ed. CID, Mexico. URL: Shttp://www.iapqroo.org.mx/website/biblioteca/los\%20ocho\%20pasos\%20para\%20el\%20analisis $\% 20$ de\%20politicas\%20publicas.pdf $>$.

BARDIN, L. Análise de conteúdo. Lisboa: Edições 70. 1979.

BARNES, C. Emancipatory Disability Researrch: projet or process? Public Lecture at Citu chambers, centre for Disability Studies, University of Leeds. 2001.

BARNES, C. Disability, Disability Studies and Academy. In: Disabling - Enabling Environments. SWAIN, J. et. al.(org). Londres: Sage Publications.2004.

BARNES, C. Independent Futures: policies practices and the illusion of inclusion. Centre fro Disabiliy Studies, School of Sociology and Social Policy, University of Leeds.2006.

BARNES, C.; MERCER, G. Theorising and Researching Disability from a Social Model Perspective. In: 'Implementing the Social Model of Disability: Theory and Research' edited by Colin Barnes and Mercer (2004); Leeds: The Disability Press, pp. 1-17. 2004

BARNES, C.; MERCER, G. Exploring disability. 2a edição. Polity, Cambridge, UK. 2010.

BATES, K., GOODLEY, D.: RUNSWICK-COLE, K. Precarious lives and resistant possibilities: the labour of people with learning disabilities in times of austerity, Disability \& Society, 32:2, 160 $175,2017$.

BRASIL. Lei $n^{\circ}$ 8.742, de 7 de dezembro de 1993. Dispõe sobre a organização da Assistência Social e dá outras providências.1993. URL: <://www.planalto.gov.br/ccivil_03/leis/L8742.htm>

BRASIL. Decreto Legislativo $N^{\circ} 186$. Aprova o texto da Convenção sobre os Direitos das Pessoas com Deficiência e de seu Protocolo Facultativo, assinados em Nova Iorque, em 30 de março de 2007. 2008. URL: <http://www.planalto.gov.br/ccivil_03/constituicao/congresso/DLG/DLG-1862008.htm>

BRASIL. Decreto $n^{\circ} 7.612$, de 17 de novembro de 2011. Institui o Plano Nacional dos Direitos da Pessoa com Deficiência - Plano Viver sem Limite. 2011. URL: <http://www.planalto.gov.br/ccivil_03/_ato2011-2014/2011/decreto/d7612.htm>

BRASIL. Portaria MS/GM n ${ }^{\circ} 793$, de 24 de abril de 2012 - Institui da Rede de Cuidados à Saúde da Pessoa com Deficiência e a Portaria MS/GM no 835, de 25 de abril de 2012 - Institui incentivos financeiros de investimento e de custeio para o Componente Atenção Especializada da Rede de Cuidados à Saúde da Pessoa com Deficiência no âmbito do Sistema Único de Saúde. 2012.

BRASIL. Lei. $n^{o}$ 13.146, de 6 de julho de 2015. Institui a Lei Brasileira de Inclusão da Pessoa com Deficiência (Estatuto da Pessoa com Deficiência). 2015. 
Campos Neutrais - Revista Latino-Americana de Relações Internacionais Vol. 2, No 1, Janeiro- Abril de 2020. Santa Vitória do Palmar - RS.

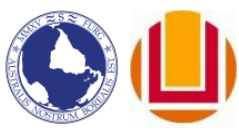

BRASIL. Constituição da República Federativa do Brasil. 1988. URA: <www.planalto.gov.br/ccivil_03/constituicao/constituicao.htm>

BRASIL. Lei $n^{\circ} 7.853$, de 24 de outubro de 1989.Dispõe sobre o apoio às pessoas portadoras de deficiência, sua integração social, sobre a Coordenadoria Nacional para Integração da Pessoa Portadora de Deficiência - $\quad$ Corde. $1989 . \quad$ URL: http://www.planalto.gov.br/ccivil_03/LEIS/L7853.htm. Acessado em: 25/11/2015.

BRASIL. Lei $n^{o}$ 8.213, de 24 de julho de 1991. Dispõe sobre os Planos de Benefícios da Previdência Social e dá outras providências. 1991. URL: <http://www.planalto.gov.br/ccivil_03/leis/L8213cons.htm>.

BRASIL. Lei $n^{\circ}$ 8.742, de 7 de dezembro de 1993 (Publicação original). Dispõe sobre a organização da Assistência Social e dá outras providências. 1993. URL: <http://www2.camara.leg.br/legin/fed/lei/1993/lei-8742-7-dezembro-1993-363163-publicacaoor iginal-1-pl.html>. Acessado em: 28/12/2016.

BRASIL. Decreto $n^{\circ} 3.298$, de 20 de dezembro de 1999.Regulamenta a Lei $n^{\circ} 7.853$, de 24 de outubro de 1989, dispõe sobre a Política Nacional para a Integração da Pessoa Portadora de Deficiência, consolida as normas de proteção, e dá outras providências. 1999. URL: http://www.planalto.gov.br/ccivil_03/decreto/d3298.htm. Acessado em: 24/11/2015.

BRASIL. Decreto $n^{o} 5.296$. Regulamenta as Leis $\mathrm{n}^{\mathrm{os}} 10.048$, de 8 de novembro de 2000 , que dá prioridade de atendimento às pessoas que especifica, e 10.098, de 19 de dezembro de 2000, que estabelece normas gerais e critérios básicos para a promoção da acessibilidade das pessoas portadoras de deficiência ou com mobilidade reduzida, e dá outras providências. 2004. URL: <http://www.planalto.gov.br/ccivil_03/_ato2004-2006/2004/decreto/d5296.htm>.

BUTLER, J. Performativity, Precarity and Sexual Politics. AIBR. Revista De Antropología Iberoamericana 4 (3) i-xiii.2009.

COSTA, M.D. Movimentos Sociais e Cidadania: uma nova dimensão para a política social no Brasil. Rev. Adm. pública. Rio de Janeiro, 22(2).1988.

CRP - Constituição da República Portuguesa. Artigo 71.1976.

CRP - Constituição da República Portuguesa. Decreto de aprovação da Constituição de 10 de abril. Diário Oficial, serie $1 \quad \mathrm{n}^{\mathrm{o}}$ 86. URL: URL: <http://www.cne.pt/sites/default/files/dl/crp_1976.pdf>

CVI - Rio - Centro de Vida Independente do Rio de janeiro Nossa História. 2016.URL:<http://www.cvi-rio.org.br/site/cvirio/>. Acessado em: 11/12/2016.

DAGNINO, E.¿Sociedade civil, participação e cidadania: de que estamos falando? En Daniel Mato (coord.), Políticas de ciudadanía y sociedad civil en tiempos de globalización. Caracas: FACES, Universidad Central de Venezuela. 2004.

D'AMARAL, T.C. Impossível aceitar o permanente desrespeito à lei de cotas. Instituto Brasileiro dos Direitos das Pessoas com Deficiência. Rio, 30 de outubro. 2015. URA:<http://www.ibdd.org.br/noticias/artigo-teresa-

$32 \% 20$ Impossivel\%20aceitar\%20o\%20permanente $\% 20$ desrespeito $\% 20 \mathrm{a} \% 201$ ei $\% 20 \mathrm{de} \% 20$ cotas.as p>

DAVIES, J.S. The social exclusion debate. Policy Studies, 26: 1, 3 - 27.2005.

DI GIOVANNI, G. As Estruturas Elementares das Políticas Públicas. Caderno de Pesquisa $n^{\circ} 82$. Universidade Estadual de Campinas - Unicamp. Núcleo De Estudos De Políticas Públicas Nepp.2009.

DRAKE, R.F. Understanding Disability Policies. British Library, London.1999.

ESTANQUE, E.; COSTA, H.A. Trabalho, precariedade e rebeliões sociais. Revista Crítica de Ciências Sociais, $\mathrm{n}^{\circ}$ 103. 2014. URL: http://rccs.revues.org/5519 
Campos Neutrais - Revista Latino-Americana de Relações Internacionais Vol. 2, No 1, Janeiro- Abril de 2020. Santa Vitória do Palmar - RS.

FONTES, F. Pessoas com Deficiência em Portugal. Fundação Francisco Manuel dos Santos. Lisboa, PT.2016.

GIL, M. $O$ que as empresas podem fazer pela inclusão das pessoas com deficiência. São Paulo: Instituto Ethos. 2002.

GOMES, F.G. Conflito social e Welfare State: Estado e desenvolvimento social no Brasil. Rev. Adm. Pública vol.40 n 2 Rio de Janeiro Mar./Apr. 2006. URL: <http://dx.doi.org/10.1590/S003476122006000200003>

GUERRA, J.A. 2003: Ano europeu da pessoa com deficiência. Porquê? Lerparaver.2005.

HESPANHA, P.; MONTEIRO, A.; FERREIRA, C.; RODRIGUES, F.; NUNES, M.H.; HESPANHA, M.J.; MADEIRA, R.; VAN DEN HOVEN, R.; PORTUGAL, S. Entre o Estado e o Mercado: As fragilidades das instituições de protecção social em Portugal. Coimbra: Quarteto Editora. 2000. URL: <http://santascasasdamisericordia.blogspot.pt/2008/11/entre-o-estado-e-omercado-as.html>.

IFDR - Instituto Financeiro para o Desenvolvimento Regional. Programa Nacional de Acção para $\begin{array}{lllll}o & \text { Crescimento } & e & \text { Emprego } & \text { (PNACE).[s.d.]. }\end{array}$ $<$ http://www.ifdr.pt/content.aspx?menuid=202\&eid=942>.

INE - Instituto Nacional de Estatística. 2013. URL: https://www.ine.pt. Acessado em: 29/10/2015.

LANNA JR, M.C.M. História do Movimento Político das Pessoas comDeficiência no Brasil. Secretaria de Direitos Humanos. Secretaria Nacional de Promoção dos Direitos da Pessoa com Deficiência, Brasília.2010.

PORTUGAL. Lei $n^{\circ}$ 46/2006.DR, 1 . série A n ${ }^{\circ} 165-2006$.

PORTUGAL. Lei $n^{\circ}$ 109/97. DR I Série A n. ${ }^{\circ} 106-1997$.

PORTUGAL. Lei $n^{\circ}$ 38/2004. DR I série A nº $194-2004$.

PORTUGAL. Lei $n^{\circ}$ 9/98. DR I SÉRIE-A nº $41-1998$.

NOGUEIRA, V.M.R. Estado de Bem-estar Social - origens e desenvolvimento. Katálysis $n^{\circ} 5$ jul. 2001. URL: 〈https://periodicos.ufsc.br/index.php/katalysis/article/viewFile/5738/5260>

OLIVEIRA, L.M.B. Cartilha do Censo 2010 - Pessoas com Deficiência. Brasília: SDH-PR/SNPD. 2012. URA: <http://www.pessoacomdeficiencia.gov.br/app/sites/default/files/publicacoes/ cartilhacenso-2010-pessoas-com-deficienciareduzido.pdf $>$.

OLIVEIRA, L.M.B.O Mercado de Trabalho para as Pessoas com Deficiência: censo2010. SEDPCD. [s.d.]. URA: <http://www.pessoacomdeficiencia.gov.br/app/node/767>

OURIQUES, H.R. A condição semiperiférica do Brasil na economia mundo capitalista. $3^{\circ}$ Seminário de Relações Internacionais: Graduação e Pós-graduação da ABRI Florianópolis, Campus da UFSC, 29 e 30 de set. 2016.

PAIPDI - $1^{\circ}$ Plano de Acção para a Integração das Pessoas com Deficiências ou Incapacidade (2006/2009). Gabinete da Secretária de Estado Adjunta e da Reabilitação, Secretariado Nacional para a Reabilitação e Integração das Pessoas com Deficiência. 2006. URL: <http://www.inr.pt/uploads/docs/programaseprojectos/paipdi/PAIPDIdesenv.pdf

PORTUGAL, S.; MARTINS, B.S.; RAMOS, L.M.; HESPANHA, P.; ALVES, J.; FIDALGO, J. Estudo de avaliação do impacto dos Custos Financeiros e Sociais da Deficiência - relatório final. Coimbra: Centro de Estudos Sociais. $2010 . \quad$ URL: <http://www.ces.uc.pt/myces/UserFiles/livros/1097_impactocustos\%20(2).pdf>

PORTUGAL. Decreto-Lei $n .^{\circ} 170 / 80$. DR. Serie $1-\mathrm{N}^{\circ} 124.1980$.

PORTUGAL. Decreto-Lei $n .{ }^{\circ}$ 202//96. DR, $1 .{ }^{a}$ Série-A, n. ${ }^{\circ}$ 246, de 1996.

PORTUGAL. Decreto-Lei n. ${ }^{\circ}$ 43/76. DR 16/76 SÉRIE I de 1976. 
Campos Neutrais - Revista Latino-Americana de Relações Internacionais Vol. 2, No 1, Janeiro- Abril de 2020. Santa Vitória do Palmar - RS.

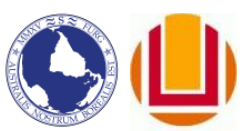

PORTUGAL. Decreto-Lei . $^{\circ}$ 513-L/79. DR. Série I n. ${ }^{\circ}$ 296/1979de 1979.

PORTUGAL. Decreto-Lei $n^{\circ}$ 174/97 DR — I SÉRIE-A N.o 165 - 1997.

PORTUGAL. Decreto-Lei $n^{\circ} 290 / 2009$. DR 1. ${ }^{\text {a }}$ série - no $197-2009$.

REIS, J. Portugal: a heterogeneidade de uma economia semiperiférica. In: Portugal: um Retrato Singular. Santos, B.S. (org). Centro de Estudos Sociais e Edições afrontamento, Porto. 1993.

RODRIGUES, M.L. O Modelo das Etapas e a Análise das Políticas Públicas In: Exercícios de Análise de Políticas Públicas. RODRIGUES, M.L. (org) Imprensa Nacional-Casa da Moeda e ISCTE-IUL. 2014.

URL: <https://www.incm.pt/portal/bo/produtos/anexos/10247020150105143732788.pdf>

RUA, M.G. Análise de Políticas Públicas: conceitos básicos. 1998. URL:< Análise_de_Políticas_Públicas_Conceitos_Básicos>

RUA, M.G. Políticas públicas. Florianópolis: Departamento de Ciências da Administração UFSC CAPES: UAB. Brasília. 2010.

SANTOS, B.S. Estado e sociedade na semiperiferia do sistema mundial: o caso português. Análise Social, vol. XXI (87-88-89), 1985-3. ${ }^{\circ}-4 .^{\circ}-5 .^{\circ}, 1985$.

SANTOS, B.S. State, wage relations and Social Welfare in the semiperiphery: the case of Portugal. $<$ <oficina do CES - ces Coimbra $\mathrm{n}^{\circ}$ 23. 1991. URL: $<$ https://estudogeral.sib.uc.pt/bitstream/10316/10931/1/State\%2c\%20Wage\%20Relations\%20and\% 20Social\%20Welfare\%20in\%20the\%20Semiperiphery.pdf>

SANTOS, B.S. O Estado, as relações salariais e o bem-estar social na semiperiferia: o caso português. In Portugal: um Retrato Singular. Santos, B.S. (org). Centro de Estudos Sociais e Edições afrontamento, Porto.1993.

SANTOS, B.S.; HESPANHA, P. O Estado, a sociedade e as políticas sociais: o caso das políticas de saúde. Revista critica de Ciências Sociais, nº 23, Coimbra, set.1987.

SDH - Secretária de Direitos Humanos; SNPDCD - Secretaria Nacional de Promoção dos Direitos da Pessoa com Deficiência. Convenção sobre os Direitos das Pessoas com Deficiência: Protocolo Facultativo à Convenção sobre os Direitos das Pessoas com Deficiência: decreto legislativo ${ }^{\circ}$ 186, de 09 de julho de 2008: decreto $\mathrm{n}^{\circ}$ 6.949, de 25 de agosto de 2009. - 4. ed., rev. e atual. Brasília. 2011. URL: <http://www.pessoacomdeficiencia.gov.br/app/sites/default/files/publicacoes/ convencaopessoascomdeficiencia.pdf

SDH/PR - Secretaria de Direitos Humanos da Presidência da República; SNPD - Secretaria Nacional de Promoção dos Direitos da Pessoa com Deficiência. Viver Sem Limite: Plano Nacional dos Direitos da Pessoa com Deficiência: SDH-PR/SNPD.2013.

SEAR - Secretaria de Estado Adjunta e da Reabilitação. $1^{\circ}$ Plano de Ação para a Integração das Pessoas com Deficiências ou Incapacidade. $1^{\mathrm{a}}$ edição, Lisboa.2006.

SEDPD - Secretaria de Estado dos Direitos da Pessoa com Deficiência. Convenção sobre os Direitos de Pessoas com Deficiência. 2008. URL: 〈http://www.pessoacomdeficiencia.sp.gov.br〉. Acessado em: 23/11/2015.

SEDPD - Secretaria de Estado dos Direitos da Pessoa com Deficiência. Um plano para o Brasil.[s.d.]. URL: < http://www.pessoacomdeficiencia.gov.br/app/viversemlimite>.

SENADO FEDERAL. Estatuto da Pessoa com deficiência. Secretaria de Editoração $e$ Publicações Coordenação de Edições Técnicas Brasília DF. 2015. URL: <https://www2.senado.leg.br/bdsf/bitstream/handle/id/513623/>

SILVA, P.N; PRAIS F.G.; SILVEIRA, A.M. Inclusão da pessoa com deficiência no mercado de trabalho em Belo Horizonte, Brasil: cenário e perspectiva. Ciência \& Saúde Coletiva, 20(8):25492558, 2015. URL:<http://www.scielo.br/pdf/csc/v20n8/1413-8123-csc-20-08-2549.pdf>. 
Campos Neutrais - Revista Latino-Americana de Relações Internacionais Vol. 2, No 1, Janeiro- Abril de 2020. Santa Vitória do Palmar - RS.

SOUZA, C. Introdução Políticas Públicas: uma revisão da literatura. Sociologias - ano 8, no 16. Porto Alegre jul/dez.2006.

SOUZA, C. Estado da arte da pesquisa em políticas públicas. In: Políticas públicas no Brasil. HOCHMAN, G.; ARRETCHE, M.; MARQUES, E. Ed. FIOCRUZ, Rio de Janeiro.2012.

TEIXEIRA, E.C. O papel das políticas públicas no desenvolvimento local e na transformação da realidade. 2002. URL: <http://www.dhnet.org.br/dados/ cursos/aatr2/a_pdf/ 03_aatr_pp_papel.pdf>

UNRIC - Centro Regional de Informação das Nações Unidas. Alguns Factos e Números sobre as Pessoas com Deficiência. 2015. Disponível: <https://www.unric.org/pt/pessoas-comdeficiencia/5459>. Acessado em: 30/10/2015.

UNRIC - Centro Regional de Informação das Nações Unidas. [s.d.]. URL: <https://www.unric.org/pt/pessoas-com-deficiencia/5459>

WALLERSTEIN, I. A Economia-Mundo Capitalista. Nova York e Londres: Cambridge University Press.1979.

WALLERSTEIN, I. World-Systems Analysis: an introduction. Duke University Prees, Durham.2004. 